\title{
New $\beta$-class milbemycin compound from Streptomyces avermitilis NEAU1069: fermentation, isolation and structure elucidation
}

\author{
Ming Wang ${ }^{1}$, Xiao-Hu Yang ${ }^{2}$, Ji-Dong Wang ${ }^{2}$, Xiang-Jing Wang ${ }^{1}$, Zheng-Jie Chen ${ }^{2}$ and Wen-Sheng Xiang ${ }^{1}$
}

The Journal of Antibiotics (2009) 62, 587-591; doi:10.1038/ja.2009.78; published online 14 August 2009

Keywords: Streptomyces avermitilis NEAU1069; $\beta$-class milbemycins; structure elucidation

\begin{abstract}
Microbial metabolites attract increasing attention as potential pesticides. They are expected to overcome the resistance and pollution that have accompanied the use of synthetic pesticides. ${ }^{1,2}$ Our experiments were conducted as part of a program to screen new antibiotics for pesticides and antiparasitic veterinary drugs, or as semisynthetic intermediates. As a result, a new compound 1, two known milbemycins (compounds $\mathbf{2}$ and $\mathbf{3}$, Figure 1 ) and avermectin $\mathrm{B}_{1 \mathrm{a}}$ were isolated from the fermentation broth of Streptomyces avermitilis NEAU1069 strain, which was newly obtained from a soil sample. The structures of compounds 1, 2 and 3 were elucidated by UV, IR, electrospray ionization (ESI)-MS, high-resolution ESI (HRESI)-MS, extensive 1D and 2D NMR analyses, and a comparison with data reported in literature. Their structures are similar to milbemycin $\beta 3,{ }^{3-6} \beta 4,{ }^{7,8}$ $\beta 13,{ }^{9} \beta 14^{9}$ and aromatic S541 analogs, ${ }^{10}$ which are generated by the nemadectin-producing strains S. thermoarchaensis NCIB 12015 and NCIB 12212. However, there are differences among them at positions $\mathrm{C}-23$ and C-25. $\beta$-Class milbemycins have not been previously reported as being from $S$. avermitilis. ${ }^{3-10}$ This paper describes the fermentation, isolation and identification of compounds 1, 2 and 3. Moreover, the spectroscopic data of compounds $\mathbf{2}$ and $\mathbf{3}$ are reported for the first time (although the structures of compounds $\mathbf{2}$ and $\mathbf{3}$ could be searched in SciFinder Scholar (Chemical Abstract Service, ACS; http://www.cas.org/products/sfacad/index.html), no reference was cited. Furthermore, they were not reported). The discovery of these three compounds possibly has an important role in understanding and perfecting the proposed pathways of avermectins and milbemycins. In addition, it is significant that they are useful intermediates in the preparation of other derivatives. ${ }^{11}$
\end{abstract}

\section{MATERIALS AND METHODS}

Screening, isolation and identification of the producing organism The agar plate dilution method was used to separate the microorganism reported in this paper. A sample soil of $0.5 \mathrm{~kg}$ obtained from Harbin city,
China, was taken in a sterilized test tube and sterilized water was added thereto. After $10 \mathrm{~min}$ of setting, supernatant was obtained. The supernatant thus obtained was 100-fold diluted using sterilized water, and $0.1 \mathrm{ml}$ of the diluted solution was distributed onto a yeast-malt extract (yeast extract $4 \mathrm{gl}^{-1}$, malt extract $10 \mathrm{gl}^{-1}$, glucose $4 \mathrm{gl}^{-1}$, agar $20 \mathrm{gl}^{-1}$ and distilled water $1 \mathrm{l}, \mathrm{pH} 7.0-7.2$ ) taken in a petri dish and cultured at $28^{\circ} \mathrm{C}$ for 15 days. Colonies formed on the yeast-malt extract agar, from which a single colony was isolated using a sterilized needle. The obtained colony was transferred to a fresh yeast-malt extract agar at regular intervals for 10 days, followed by submerged fermentation. Metabolites were extracted by adding $4 \mathrm{ml}$ methanol to $2 \mathrm{ml}$ whole broth and mixing intermittently for $3 \mathrm{~h}$. The extracts were examined on two-spotted spider mites to determine whether they have acaricidal activity. Then, the metabolites with acaricidal activity were purified and their structures were determined.

To identify the isolated strain with acaricidal activity in the metabolites, morphological properties of cells, cultural characteristics of cells, morphological characteristics of colonies, physiological characteristics, utilization of a carbon source and 16S rDNA (Accession No: DQ768097 in National Center for Biological Information, Bethesda, MD, USA) were investigated. The strain was named S. avermitilis NEAU1069. It has been deposited at the China General Microbiology Culture Collection Center, Beijing, China (Accession No: CGMCC 2943).

\section{Fermentation}

The strain was maintained on a YMS (yeast extract-malt extract-soluble starch) medium containing soluble starch (Beijing Ao Bo Xing, Beijing, China) $10 \mathrm{~g}$, yeast extract (Beijing Ao Bo Xing) $2 \mathrm{~g}, \mathrm{KNO}_{3} 1 \mathrm{~g}$ and agar $20 \mathrm{~g}$ in 1.01 tap water, $\mathrm{pH}$ 7.0. The seed medium consisted of glucose (Beijing Ao Bo Xing) $20 \mathrm{~g}$, soybean flour (Comwin, Beijing, China) $15 \mathrm{~g}$ and yeast autolysate (Beijing Ao Bo Xing) $5.0 \mathrm{~g}$ in 1.01 water, $\mathrm{pH}$ 7.0. Both the media were sterilized at $121^{\circ} \mathrm{C}$ for $20 \mathrm{~min}$. Slant cultures were incubated for $6-8$ days at $28^{\circ} \mathrm{C}$.

A total of $10 \mathrm{ml}$ of sterile water was added to the slant of the YMS medium. The spores were scraped and transferred onto a sterile tube containing glass beads; the spore suspension was then filtered through six layers of a sterile filter cheesecloth and adjusted to $10^{7}-10^{8}$ c.f.u ml ${ }^{-1}$. A $2.0 \mathrm{ml}$ of the spore suspension was inoculated into a $250-\mathrm{ml}$ flask containing $25 \mathrm{ml}$ of seed medium and incubated at $28^{\circ} \mathrm{C}$ for 24 h, shaken at 250 r.p.m. Then, $8 \mathrm{ml}$ of the culture was

${ }^{1}$ Department of Biochemical Engineering, School of Life Science, Northeast Agricultural University, Harbin, China and ${ }^{2}$ Zhejiang Hisun Pharmaceutical, Taizhou, Zhejiang, China Correspondence: Professor W-S Xiang, School of Life Science, Northeast Agricultural University, Harbin 150030, China.

E-mail: xiangwensheng@yahoo.com.cn

Received 26 April 2009; revised 14 July 2009; accepted 15 July 2009; published online 14 August 2009 


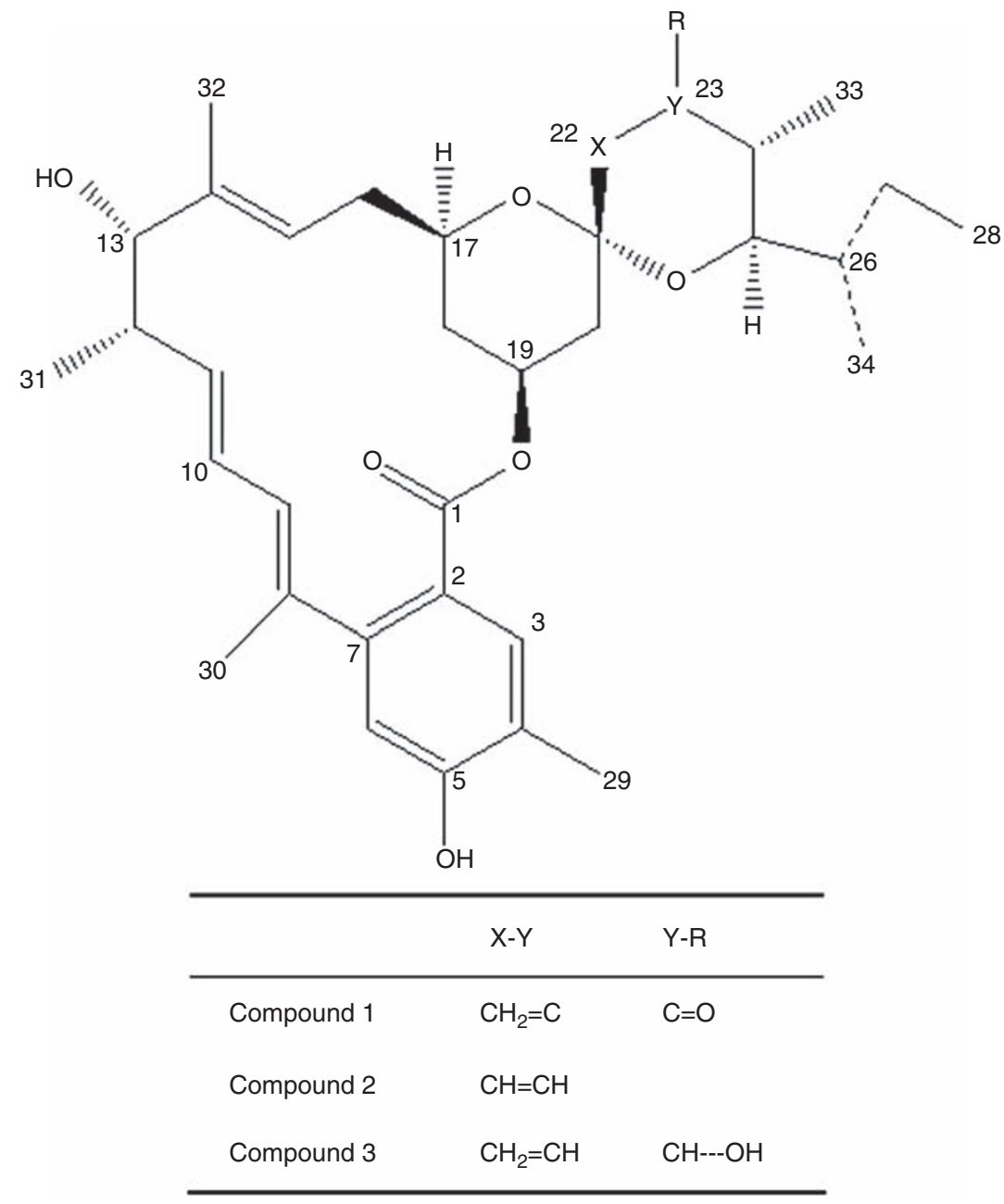

The structures of compound 1,2 and 3

Figure 1 The structures of compounds 1, 2 and $\mathbf{3}$.

transferred into a 1-1 Erlenmeyer flask containing $100 \mathrm{ml}$ of the producing medium consisting of corn starch (Comwin) 10\%, soybean powder 1\%, cotton flour (Comwin) $1 \%, \alpha$-Amylase (Beijing Ao Bo Xing) $0.02 \%, \mathrm{NaCl} 0.1 \%$, $\mathrm{K}_{2} \mathrm{HPO}_{4} 0.2 \%, \mathrm{MgSO}_{4} \cdot 7 \mathrm{H}_{2} \mathrm{O} 0.1 \%, \mathrm{CaCO}_{3} \cdot 0.7 \%$ and $\mathrm{pH} 7.0$, before sterilization. Fermentation was carried out at $28^{\circ} \mathrm{C}$ for $12-13$ days on a rotary shaker at 250 r.p.m.

\section{Isolation and purification}

A total of 31 of broth from 40 producing fermentations was filtered. The resulting cake was washed with water (31), and both filtrate and wash were discarded. Methanol (11) was used to extract the washed cake. The $\mathrm{MeOH}$ extract was evaporated under reduced pressure to approximately 0.21 at $45{ }^{\circ} \mathrm{C}$ and the resulting concentrate was extracted three times using an equal volume of EtOAc. The combined EtOAc phase was concentrated under reduced pressure to yield $5 \mathrm{~g}$ of oily substances. The residual oily substance was chromatographed on silica gel (Qingdao Haiyang Chemical Group, Qingdao, Shandong, China; 100-200 mesh) and eluted with a petroleum $\left(60^{\circ} \mathrm{C}\right.$ $\left.-90^{\circ} \mathrm{C}\right)$-acetone mixture $(95: 5,75: 25$ and 50:50, v/v). The fractions eluted with the petroleum-acetone mixture (95:5-75:25, v/v) were combined and evaporated to obtain a crude mixture. The crude mixture was applied to a silica gel column and eluted with a petroleum-EtOAc mixture (95:5, 85:25, 75:25, $65: 35$ and $50: 50, \mathrm{v} / \mathrm{v}$ ) to give five fractions.

Semipreparative HPLC (Agilent 1100, Zorbax SB-C18, $5 \mu \mathrm{m}, 250 \times 9.4 \mathrm{~mm}$ i.d.; Agilent, Palo Alto, CA, USA) and preparative HPLC (Shimadzu LC-8A, Shimadzu-C18, $5 \mu \mathrm{m}, 250 \times 20 \mathrm{~mm}$ i.d.; Shimadzu, Kyoto, Japan) were further performed to obtain pure compounds. The eluates were monitored using a photodiode array detected at $220 \mathrm{~nm}$, and the flow rates were $1.5 \mathrm{ml} \mathrm{min}^{-1}$ for the semipreparative HPLC and $20 \mathrm{ml} \mathrm{min}^{-1}$ for the preparative HPLC at room temperature. Fraction one was purified by semipreparative HPLC using a solvent containing a $\mathrm{CH}_{3} \mathrm{OH}-\mathrm{H}_{2} \mathrm{O}$ mixture $(97: 3, \mathrm{v} / \mathrm{v})$ to obtain $2\left(\mathrm{t}_{\mathrm{R}} 10.6 \mathrm{~min}\right.$, $13 \mathrm{mg}$ ). Fraction two was also subjected to silica gel elution using petroleumEtOAc mixture (85:15 and 75:25, v/v) to obtain two subfractions. Subfraction one was further separated by semipreparative HPLC elution using $\mathrm{CH}_{3} \mathrm{OH}-$ $\mathrm{H}_{2} \mathrm{O}$ mixture (92:8, v/v) to afford compound $1\left(t_{\mathrm{R}} 12.3 \mathrm{~min}, 11 \mathrm{mg}\right)$. Subfraction two was purified by preparative HPLC using $\mathrm{CH}_{3} \mathrm{OH}-\mathrm{H}_{2} \mathrm{O}$ mixture (8:2, $\mathrm{v} / \mathrm{v})$ to obtain $3\left(t_{\mathrm{R}} 17.1 \mathrm{~min}, 24 \mathrm{mg}\right)$.

\section{General}

Melting points were measured using a Fisher-Johns micro-melting point apparatus (corrected; Fisher-Johns, Pittsburgh, PA, USA); UV spectra were obtained on a Varian CARY 300 BIO spectrophotometer (Varian, Palo Alto, CA, USA); IR spectra were recorded on a Nicolet Magna FT-IR 750 spectrometer (Nicolet Magna, Madison, WI, USA); ${ }^{1} \mathrm{H}$ and ${ }^{13} \mathrm{C}-\mathrm{NMR}$ spectra were measured using a Bruker DRX-400 $\left(400 \mathrm{MHz}\right.$ for ${ }^{1} \mathrm{H}$ and $100 \mathrm{MHz}$ for $\left.{ }^{13} \mathrm{C}\right)$ spectrometer (Bruker, Rheinstetten, Germany); chemical shifts are reported in p.p.m $(\delta)$ using the residual $\mathrm{CHCl}_{3}\left(\delta_{\mathrm{H}} 7.26 ; \delta_{\mathrm{C}} 77.0\right)$ as an internal standard, and coupling constant $(J)$ in $\mathrm{Hz} .{ }^{1} \mathrm{H}$ and ${ }^{13} \mathrm{C}$-NMR assignments were supported by ${ }^{1} \mathrm{H}-{ }^{1} \mathrm{H}$ COSY, heteronuclear multiple quantum coherence and heteronuclear multiple bond correlation (HMBC) experiments. The ESI-MS and HRESI-MS spectra were taken on a Q-TOF Micro LC-MS-MS mass spectrometer (Waters, 
Table $1^{1} \mathrm{H}$ and ${ }^{13} \mathrm{C}$-NMR data of compounds $1-3$ (coupling constants in parenthesis)

\begin{tabular}{|c|c|c|c|c|c|c|}
\hline \multirow[b]{2}{*}{ Position } & \multicolumn{3}{|c|}{ Proton } & \multicolumn{3}{|c|}{ Carbon } \\
\hline & 1 & 2 & 3 & 1 & 2 & 3 \\
\hline 1 & & & & $168.9 \mathrm{~s}^{\mathrm{a}}$ & $169.1 \mathrm{~s}$ & $169.0 \mathrm{~s}$ \\
\hline 2 & & & & $123.6 \mathrm{~s}$ & $123.8 \mathrm{~s}$ & $123.3 \mathrm{~s}$ \\
\hline 3 & $7.41 \mathrm{~s}$ & $7.39 \mathrm{~s}$ & $7.39 \mathrm{~s}$ & $132.3 \mathrm{~d}$ & $132.1 \mathrm{~d}$ & $132.2 \mathrm{~d}$ \\
\hline 4 & & & & $122.5 \mathrm{~s}$ & $122.4 \mathrm{~s}$ & $122.7 \mathrm{~s}$ \\
\hline 5 & & & & $155.8 \mathrm{~s}$ & $155.6 \mathrm{~s}$ & $156.1 \mathrm{~s}$ \\
\hline 6 & $6.61 \mathrm{~s}$ & $6.61 \mathrm{~s}$ & $6.61 \mathrm{~s}$ & $114.3 \mathrm{~d}$ & $114.2 \mathrm{~d}$ & $114.2 \mathrm{~d}$ \\
\hline 7 & & & & $144.5 \mathrm{~s}$ & $144.3 \mathrm{~s}$ & $144.3 \mathrm{~s}$ \\
\hline 8 & & & & $135.0 \mathrm{~s}$ & $135.0 \mathrm{~s}$ & $135.1 \mathrm{~s}$ \\
\hline 9 & $5.70 \mathrm{~d}(10.8)$ & $5.73 \mathrm{~d}(10.8)$ & $5.68 \mathrm{dd}(1.1,10.9)$ & $128.5 \mathrm{~d}$ & $128.5 \mathrm{~d}$ & $128.4 \mathrm{~d}$ \\
\hline 10 & $6.16 \mathrm{dd}(10.8,15.0)$ & $6.17 \mathrm{dd}(10.9,15.1)$ & $6.16 \mathrm{dd}(10.9,15.1)$ & $127.3 \mathrm{~d}$ & $127.4 \mathrm{~d}$ & $127.3 \mathrm{~d}$ \\
\hline 11 & $5.45 \mathrm{dd}(9.6,15.2)$ & $5.45 \mathrm{dd}(9.6,14.5)$ & $5.45 \mathrm{dd}(9.6,15.1)$ & $134.5 \mathrm{~d}$ & $134.3 d$ & $134.3 \mathrm{~d}$ \\
\hline 12 & $2.64 \mathrm{~m}$ & $2.62 \mathrm{~m}$ & $2.61 \mathrm{~m}$ & $40.7 \mathrm{~d}$ & $40.6 \mathrm{~d}$ & $40.6 \mathrm{~d}$ \\
\hline 13 & $4.02 \mathrm{br} \mathrm{s}$ & 4.02 br s & 4.02 br s & $79.1 \mathrm{~d}$ & $79.1 \mathrm{~d}$ & $79.1 \mathrm{~d}$ \\
\hline 14 & & & & $138.3 \mathrm{~s}$ & $137.8 \mathrm{~s}$ & $138.3 \mathrm{~s}$ \\
\hline 15 & 5.17 br d (8.6) & 5.21 br d (8.7) & $5.20 \mathrm{~d}(8.9)$ & $117.4 \mathrm{~d}$ & $117.7 \mathrm{~d}$ & $117.2 \mathrm{~d}$ \\
\hline 16 & $2.28 \mathrm{~m}$ & $\begin{array}{l}2.32 \mathrm{~m} \\
2.39 \mathrm{~m}\end{array}$ & $2.34 \mathrm{~m}$ & $33.1 \mathrm{t}$ & $33.7 \mathrm{t}$ & $33.4 \mathrm{t}$ \\
\hline 17 & $3.76 \mathrm{~m}$ & $3.98 \mathrm{~m}$ & $3.84 \mathrm{~m}$ & $68.6 \mathrm{~d}$ & $68.6 \mathrm{~d}$ & $68.7 \mathrm{~d}$ \\
\hline 18 & 0.78 q (12.0) & $0.79 q(12.1)$ & 0.79 q (12.4) & $36.1 \mathrm{t}$ & $36.6 \mathrm{t}$ & $36.3 \mathrm{t}$ \\
\hline & $1.97 \mathrm{~m}$ & $1.97 \mathrm{~m}$ & $1.97 \mathrm{~m}$ & & & \\
\hline 19 & $5.43 \mathrm{~m}$ & $5.43 \mathrm{~m}$ & $5.37 \mathrm{~m}$ & $67.4 \mathrm{~d}$ & $67.9 \mathrm{~d}$ & $67.2 \mathrm{~d}$ \\
\hline 20 & $1.47 \mathrm{t}(12.0)$ & $1.54 \mathrm{~m}$ & $1.47 \mathrm{t}(6.9)$ & $40.8 \mathrm{t}$ & $40.7 \mathrm{t}$ & $41.0 \mathrm{t}$ \\
\hline & $2.20 \mathrm{~m}$ & $1.98 \mathrm{~m}$ & $1.98 \mathrm{~m}$ & & & \\
\hline 21 & & & & $100.8 \mathrm{~s}$ & $96.0 \mathrm{~s}$ & $99.9 \mathrm{~s}$ \\
\hline 22 & $2.47 \mathrm{br} \mathrm{s}$ & $5.55 \mathrm{dd}(2.6,9.8)$ & $\begin{array}{l}1.67 \mathrm{dd}(3.0,14.1) \\
1.96 \mathrm{~m}\end{array}$ & $51.6 \mathrm{t}$ & $128.1 \mathrm{~d}$ & $41.3 \mathrm{t}$ \\
\hline 23 & & $5.74 \mathrm{dd}(1.7,9.8)$ & $3.83 \mathrm{br} \mathrm{s}$ & $207.4 \mathrm{~s}$ & $136.1 \mathrm{~d}$ & $70.2 \mathrm{~d}$ \\
\hline 24 & $2.45 \mathrm{~m}$ & $2.27 \mathrm{~m}$ & $1.64 \mathrm{~m}$ & $46.6 \mathrm{~d}$ & $30.6 \mathrm{~d}$ & $35.8 d$ \\
\hline 25 & $3.51 \mathrm{~d}(10.4)$ & $3.48 \mathrm{dd}(1.7,10.0)$ & $3.55 \mathrm{dd}(1.2,10.7)$ & $76.8 \mathrm{~d}$ & $75.2 \mathrm{~d}$ & $71.3 \mathrm{~d}$ \\
\hline 26 & $1.58 \mathrm{~m}$ & $1.58 \mathrm{~m}$ & $1.53 \mathrm{~m}$ & $36.1 \mathrm{~d}$ & $35.3 d$ & $35.2 \mathrm{~d}$ \\
\hline 27 & $1.52 \mathrm{~m}$ & $1.50 \mathrm{~m}$ & $1.49 \mathrm{~m}$ & $27.4 \mathrm{t}$ & $27.6 \mathrm{t}$ & $27.4 \mathrm{t}$ \\
\hline 28 & $0.96 \mathrm{t}(7.6)$ & $0.93 \mathrm{t}(7.4)$ & 0.95 t (7.3) & $12.4 \mathrm{q}$ & $12.1 \mathrm{q}$ & $12.5 q$ \\
\hline 29 & $2.23 \mathrm{br} \mathrm{s}$ & $2.24 \mathrm{br} \mathrm{s}$ & $2.21 \mathrm{br} \mathrm{s}$ & $15.3 \mathrm{q}$ & $15.3 \mathrm{q}$ & $15.3 \mathrm{q}$ \\
\hline 30 & $2.07 \mathrm{br} \mathrm{s}$ & $2.08 \mathrm{br} \mathrm{s}$ & $2.06 \mathrm{~d}(1.1)$ & $18.3 \mathrm{q}$ & $18.2 \mathrm{q}$ & $18.2 \mathrm{q}$ \\
\hline 31 & $1.21 \mathrm{~d}(6.9)$ & $1.21 \mathrm{~d}(6.9)$ & $1.21 \mathrm{~d}(6.9)$ & $18.4 \mathrm{q}$ & $18.3 \mathrm{q}$ & $18.4 \mathrm{q}$ \\
\hline 32 & $1.62 \mathrm{br} \mathrm{s}$ & $1.63 \mathrm{br} \mathrm{s}$ & $1.63 \mathrm{br} \mathrm{s}$ & $15.1 \mathrm{q}$ & $15.1 \mathrm{q}$ & $15.1 \mathrm{q}$ \\
\hline 33 & $0.97 \mathrm{~d}(6.7)$ & $0.91 \mathrm{~d}(7.1)$ & $0.91 \mathrm{~d}(6.9)$ & $8.8 \mathrm{q}$ & $16.4 \mathrm{q}$ & $13.8 \mathrm{q}$ \\
\hline 34 & $0.97 \mathrm{~d}(6.7)$ & $0.92 \mathrm{~d}(6.6)$ & $0.86 \mathrm{~d}(6.4)$ & $11.4 \mathrm{q}$ & $12.8 \mathrm{q}$ & $11.5 \mathrm{q}$ \\
\hline
\end{tabular}

BBy DEPT sequence.

Milford, MA, USA). Optical rotation was measured on a Perkin-Elmer 341 Polarimeter (Perkin-Elmer, Fremont, CA, USA).

Compound (1, Figure 1) $\mathrm{C}_{34} \mathrm{H}_{46} \mathrm{O}_{7}$, white amorphous powder; mp. 98-100 ${ }^{\circ} \mathrm{C} ;[\alpha]_{\mathrm{D}}^{25}+74^{\circ}(c 0.031, \mathrm{EtOH}) ; \mathrm{UV}(\mathrm{EtOH}) \lambda_{\max } \mathrm{nm}(\log \varepsilon)$ : 200 (4.57), 243 (4.25); IR (KBr), $v_{\max } \mathrm{cm}^{-1}: 3448,1701,2927,1457$, 1379, 1277, 1235, 1151, 989; ${ }^{1} \mathrm{H}-\mathrm{NMR}\left(400 \mathrm{MHz}, \mathrm{CDCl}_{3}\right)$ and ${ }^{13} \mathrm{C}$-NMR $\left(100 \mathrm{MHz}, \mathrm{CDCl}_{3}\right)$, for data see Table 1; ESI-MS $\mathrm{m} / \mathrm{z}$ $565[\mathrm{M}-\mathrm{H}]^{-}$; HRESI-MS $\mathrm{m} / \mathrm{z} 589.3093[\mathrm{M}+\mathrm{Na}]^{+}$; calculated for $\mathrm{C}_{36} \mathrm{H}_{48} \mathrm{O}_{7} \mathrm{Na} 589.3136$.

Compound (2, Figure 1) $\mathrm{C}_{34} \mathrm{H}_{46} \mathrm{O}_{6}$, white amorphous powder; mp. $124-126^{\circ} \mathrm{C} ;[\alpha]_{\mathrm{D}}^{25}+166^{\circ}(c 0.060, \mathrm{EtOH}) ; \mathrm{UV}(\mathrm{EtOH}) \lambda_{\max } \mathrm{nm}$ $(\log \varepsilon): 200$ (4.88), 246 (4.57); IR (KBr), $v_{\max } \mathrm{cm}^{-1}$ : 3448, 1700, 2926, 1457, 1378, 1280, 1159, 997; ${ }^{1} \mathrm{H}-\mathrm{NMR}\left(400 \mathrm{MHz}, \mathrm{CDCl}_{3}\right)$ and ${ }^{13} \mathrm{C}-\mathrm{NMR}\left(100 \mathrm{MHz}, \mathrm{CDCl}_{3}\right)$ for data see Table 1 ; ESI-MS $\mathrm{m} / \mathrm{z}$ $551[\mathrm{M}+\mathrm{H}]^{+}$; HRESI-MS $\mathrm{m} / \mathrm{z} 573.3180[\mathrm{M}+\mathrm{Na}]^{+}$; calculated for $\mathrm{C}_{36} \mathrm{H}_{48} \mathrm{O}_{6} \mathrm{Na} 573.3187$.
Compound (3, Figure 1) $\mathrm{C}_{34} \mathrm{H}_{48} \mathrm{O}_{7}$, white amorphous powder; mp. $150-153^{\circ} \mathrm{C} ;[\alpha]_{\mathrm{D}}^{25}+113^{\circ}(c 0.135, \mathrm{EtOH}) ; \mathrm{UV}(\mathrm{EtOH}) \lambda_{\max } \mathrm{nm}$ $(\log \varepsilon): 201$ (4.66), 247 (4.40); IR (KBr), $v_{\max } \mathrm{cm}^{-1}$ : 3446, 1701, 2928, 1456, 1381, 1280, 1164, 997; ${ }^{1} \mathrm{H}-\mathrm{NMR}\left(400 \mathrm{MHz}, \mathrm{CDCl}_{3}\right)$ and ${ }^{13} \mathrm{C}-\mathrm{NMR}\left(100 \mathrm{MHz}, \mathrm{CDCl}_{3}\right)$, for data see Table 1; ESI-MS m/z 567 $[\mathrm{M}-\mathrm{H}]^{-}$; HRESI-MS $\mathrm{m} / z \quad 591.3315 \quad[\mathrm{M}+\mathrm{Na}]^{+}$; calculated for $\mathrm{C}_{36} \mathrm{H}_{50} \mathrm{O}_{7} \mathrm{Na} 591.3292$.

Compound 1 was isolated as a white amorphous powder. Its molecular formula was determined to be $\mathrm{C}_{34} \mathrm{H}_{46} \mathrm{O}_{7}$ on the basis of HRESI-MS at $m / z 589.3093[\mathrm{M}+\mathrm{Na}]^{+}$(calculated as 589.3136 for $\mathrm{C}_{34} \mathrm{H}_{46} \mathrm{NaO}_{7}$ ) and ${ }^{13} \mathrm{C}-\mathrm{NMR}$ data (Table 1). The IR spectrum of 1 showed hydroxyl absorption at $3448 \mathrm{~cm}^{-1}$. ${ }^{1} \mathrm{H}-\mathrm{NMR}$ data of 1 indicated one triplet aliphatic methyl signal at $\delta 0.96$; three doublet aliphatic methyl signals at $\delta 0.97,0.97,1.21$; three olefinic or aromatic methyl signals at $\delta 1.62,2.07,2.23$; and two downfield singlet proton signals at $\delta 7.41$ and 6.61 . Its ${ }^{13} \mathrm{C}-\mathrm{NMR}$ spectrum displayed 34 carbon 


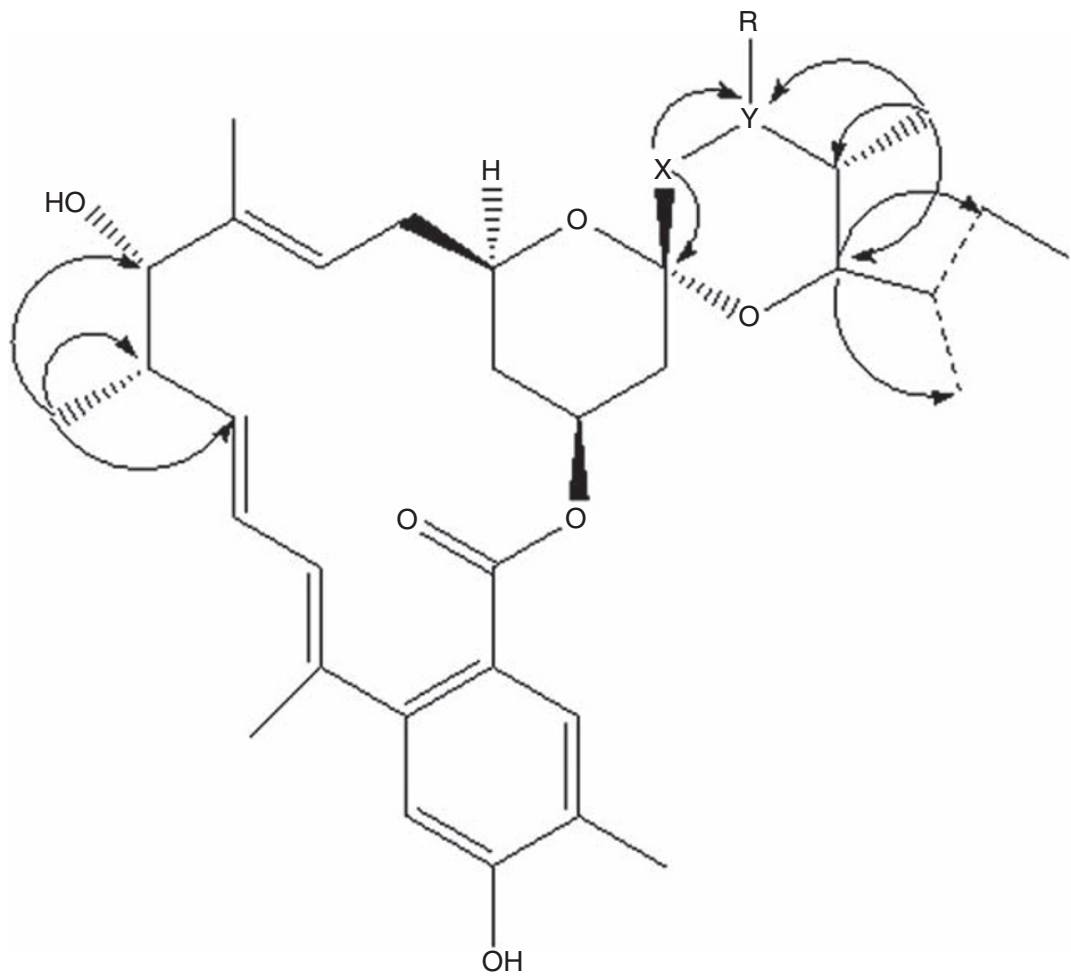

The key HMBC correlations of compound 1,2 and 3

Figure 2 The key heteronuclear multiple bond correlations (HMBC) of compounds 1, 2 and $\mathbf{3}$.

signals, including 1 carbonyl, 1 ester carbonyl, $12 s p^{2}$ carbons, 7 methyls, 5 methylenes and 7 aliphatic methines (including 4 oxygenated and 1 ketal carbon). Comparing the ${ }^{1} \mathrm{H}$ and ${ }^{13} \mathrm{C}-\mathrm{NMR}$ data with those of avermectin ${ }^{12}$ suggested that compound 1 may be a derivative of avermectin aglycone. By a detailed comparison of the NMR data of 1 with those of milbemycin $\beta 3,{ }^{3-6} \beta 4,{ }^{7,8} \beta 13$ and ${ }^{9} \beta 14^{9}$ isolated from the milbemycin-producing strain, it was revealed that compound 1 was similar to milbemycin $\beta 3$ except for the differences observed in C-13, C-23 and C-25 positions. In the HMBC spectrum, the observed correlation between $\delta_{\mathrm{H}} 1.21$ and $\delta_{\mathrm{C}} 134.5,40.7,79.1$ showed that $\mathrm{C}-13$ was substituted by a hydroxyl group (Figure 2). Both the HMBC correlated signals of $\delta_{\mathrm{H}} 0.97, \delta_{\mathrm{C}} 76.8,46.6,207.4$ and the HMBC correlated signals of $\delta_{\mathrm{H}} 2.47, \delta_{\mathrm{C}} 100.8,207.4$ indicated that the carbonyl group was in $\mathrm{C}-23$ (Figure 2). The remaining one aliphatic methylene, one aliphatic methine, one doublet aliphatic methyl and one triplet aliphatic methyl showed the presence of an isopropyl group. The three bonds' correlation signals between $\delta_{\mathrm{H}} 3.51$ and $\delta_{\mathrm{C}} 11.4,27.4$ assigned the second butyl group at C-25 similar to that of avermectin $B_{1 a}$. The relative stereochemistry of 1 was assigned by concurring with that of avermectin B. ${ }^{12}$

Compound 2 was obtained as a white amorphous powder. Its ${ }^{1} \mathrm{H}$ and ${ }^{13} \mathrm{C}$-NMR data were very similar to those of compound 1, except for the presence of another double bond and the absence of one carbonyl and one methylene group. The ${ }^{1} \mathrm{H}-{ }^{1} \mathrm{H}$ COSY correlation of $\delta_{\mathrm{H}} 5.55$ and $\delta_{\mathrm{H}} 5.74$, and the HMBC correlations between $\delta_{\mathrm{H}} 0.91$ and $\delta_{\mathrm{C}} 136.1$, indicated that the C-23 carbonyl and C-22 methylene (Figure 2) in $\mathbf{1}$ were replaced by one double bond in compound 2. Thus, the structure of compound 2 was established.

Compound 3 was also isolated as a white amorphous powder. Comparison of the ${ }^{1} \mathrm{H}$ and ${ }^{13} \mathrm{C}-\mathrm{NMR}$ data with those of compound 1 exhibited that the difference between compound $\mathbf{3}$ and compound $\mathbf{1}$ was only in the C-23 position, in which one carbonyl in compound 1 was replaced by a hydroxyl in compound 3 . The crossing peaks of $\delta_{\mathrm{H}} 0.91$ and $\delta_{\mathrm{C}} 70.2$ in the HMBC spectrum confirmed the hydroxyl group substituted at C-23 in compound 3 (Figure 2). Consequently, the structure of compound 3 was elucidated.

We have determined the $16 \mathrm{~S}$ rDNA sequence of the strain (DQ768097), which produces compounds 1, 2 and 3. It shared 99.05, 99.93 and $99.93 \%$ identity with the $16 \mathrm{~S}$ rDNA sequences of S. avermitilis strains NBRC 14893 (AB184632), MA-4680 (AB078897) and AF145223, respectively, thereby characterizing strain NEAU1069 as S. avermitilis. We also isolated avermectin $\mathrm{B}_{1 \mathrm{a}}$ from the $S$. avermitilis NEAU1069 fermentation broth. Furthermore, compounds 1, 2 and 3 produced by $S$. avermitilis NEAU1069 had the same isopropyl group at C-25 as avermectin. Although compounds 1, 2 and 3 are analogs of milbemycin $\beta 13$ and $\beta 14^{9}$ produced by S. bingchenggensis, the $16 \mathrm{~S}$ rDNA sequence of $S$. avermitilis NEAU1069 only shared $94.84 \%$ identity compared with that of $S$. bingchenggensis (DQ449953). $\beta$-Class milbemycin compounds isolated from $S$. avermitilis were not reported.

\section{ACKNOWLEDGEMENTS}

This study was supported by the National Natural Science Foundation of China (No. 30571234 and 30771427), the National Key Technology R\&D Program (No. 2006BAD31B) and the Program for New Century Excellent Talents in University.

1 Dayan, F. E., Cantrell, C. L. \& Duke, S. O. Natural products in crop protection. Bioorg. Med. Chem. 17, 4022-4034 (2009).

2 Copping, L. G. \& Duke, S. O Natural products that have been used commercially as crop protection agents. Pest. Manag. Sci. 63, 524-554 (2007). 
3 Davies, H. G. \& Green, R. H. Avermectins and milbemycins, part I. Chem. Soc. Rev. 20, 211-269 (1991).

4 Aoki, A., Fukuda, R. \& Nakayabu, T. Antibiotic substances. US. 3,950,360, April 13 (1976).

5 Smith, A. B., Schow, S. R., Bloom, J. D., Thompson, A. S. \& Winzenberg, K. N Total synthesis of milbemycin B3. J. Am. Chem. Soc. 104, 4015-4018 (1982).

6 Schow, S. R., Bloom, J. D., Thompson, A. S., Winzenberg, K. N. \& Smith, A. B. Total synthesis of milbemycin $\beta 3$ and its C(12) epimer. J. Am. Chem. Soc. 108, 2662-2674 (1986).

7 Nonaka, K. et al. New milbemycins from Streptomyces hygroscopicus subsp. aureola crimosus: fermentation, isolation and structure elucidation. J. Antibiot. 53, 694-704 (2000).
8 Hood, J. D. et al. A novel series of milbemycin antibiotics from Streptomyces strain E225. I. Discovery, fermentation and anthelmintic activity. J. Antibiot. 42, 1593-1598 (1989).

9 Xiang, W. S., Wang, J. D., Wang, X. J. \& Zhang, J. Two new $\beta$-Class milbemycins from Streptomyces bingchenggensis: fermentation, isolation, structure elucidation and biological properties. J. Antibiot. 60, 351-356 (2007).

10 Rudd, B. A. M. Macrolide compounds. E.P. 0,242,052, Oct 21 (1987).

11 Tsukiyama, T., Kajino, H. \& Tsukamoto, Y. Synthesis of novel 26-substituted milbemycin $A(4)$ derivatives and their acaricidal activities. J. Antibiot. 57, 446-455 (2004).

12 Springer, J. P., Arison, B. H., Hirshfrield, J. M. \& Hoogston, K. The absolute stereochemistry and conformation of avermectin $B_{2 a}$ aglycon and avermectin $B_{1 a}$. J. Am. Chem. Soc. 103, 4221-4224 (1981). 